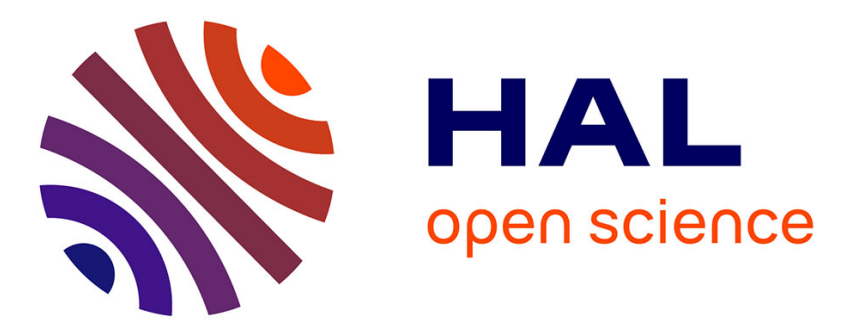

\title{
Synthesis and characterization of polyaniline-silica composites: Raspberry vs core-shell structures. Where do we stand?
}

Nicolas Roosz, Myriam Euvrard, Boris Lakard, Cédric C. Buron, Nicolas Martin, Lydie Viau

\section{To cite this version:}

Nicolas Roosz, Myriam Euvrard, Boris Lakard, Cédric C. Buron, Nicolas Martin, et al.. Synthesis and characterization of polyaniline-silica composites: Raspberry vs core-shell structures. Where do we stand?. Journal of Colloid and Interface Science, 2017, 502, pp.184 - 192. 10.1016/j.jcis.2017.04.092 . hal-01596069

\section{HAL Id: hal-01596069 \\ https://hal.science/hal-01596069}

Submitted on 26 Jan 2022

HAL is a multi-disciplinary open access archive for the deposit and dissemination of scientific research documents, whether they are published or not. The documents may come from teaching and research institutions in France or abroad, or from public or private research centers.
L'archive ouverte pluridisciplinaire HAL, est destinée au dépôt et à la diffusion de documents scientifiques de niveau recherche, publiés ou non, émanant des établissements d'enseignement et de recherche français ou étrangers, des laboratoires publics ou privés. 


\section{Synthesis and characterization of polyaniline-silica}

composites: raspberry vs core-shell structures. Where do we

stand?

Nicolas Roosz, ${ }^{a}$ Myriam Euvard, ${ }^{a}$ Boris Lakard, ${ }^{a}$ Cédric C. Buron, ${ }^{a}$ Nicolas Martin ${ }^{b}$ and Lydie $\operatorname{Viau}^{* a}$

${ }^{a}$ Institut UTINAM, UMR CNRS 6213, Univ. Bourgogne Franche-Comté, Equipe Matériaux et Surfaces Fonctionnels, 16 route de Gray, 25030 Besançon Cedex

${ }^{b}$ Institut FEMTO-ST, UMR 6174 CNRS, Univ. Bourgogne Franche-Comté, 15B, Avenue des Montboucons, 25030 Besancon Cedex, France

* To whom correspondence should be sent: E-mail: lydie.viau@univ-fcomte.fr; Fax: + (33)

03816662 88; Tel: + (33) 0381666293 


\begin{abstract}
The synthesis of polyaniline-silica composites has been reinvestigated in view of the opposing results found in the literature. Firstly, we synthesized silica particles with tunable size using the Stöber process. These silica particles have been fully characterized before being used as solid support for the polymerization of aniline. This polymerization was performed according to a published procedure where the $\mathrm{pH}$ of the reaction mixture was below the $\mathrm{pKa}$ of aniline but at a value where the silica particles surface was still slightly negatively charged. The objective of this procedure was to favor electrostatic interactions between anilinium cations and the silica surface to lead to the formation of silica-polyaniline core-shell particles. Several sets of nanocomposites were prepared under different experimental conditions (oxidant/aniline ratio, silica concentration, temperature, silica particles diameters). The study evidenced that under all the conditions used the formation of core-shell nanoparticles is impossible. However, using different particles size, noticeable morphological differences were observed. The use of large silica particles led to the formation of non-uniform polyaniline-silica composites whereas the use of smaller particles always led to raspberry-like morphology as reported by other groups in highly acidic media. The difference in morphology led to different electrical properties with electrical conductivities measured at room temperature ranging from $6.1 \times 10^{-3}$ to $2.5 \times 10^{-5}{\mathrm{~S} . \mathrm{cm}^{-1}}^{\text {. }}$
\end{abstract}

\title{
Key words
}

Silica, polyaniline, composites, raspberry, oxidative chemical polymerization 


\section{Introduction}

Organic-inorganic hybrid materials have received much attention in recent years.[1] Indeed, the resulting materials may present unique chemical and physical properties coming from the synergistic effect of both components. More particularly, the preparation, characterization and applications of polymer-silica composites are the most commonly reported in the literature.[2] Silica nanoparticles (NPs) exhibit interesting properties, such as good thermal and chemical stabilities, have tunable size and can be easily chemically modified. Intrinsically conducting polymers such as polypyrrole, polyaniline (PANI) or polythiophene can exist in different oxidation states and respond to external stimuli by changing one of their characteristics (color, conductivity, permeability).[3] In particular, PANI is a non-toxic, thermally stable and low cost polymer with relatively high conductivity that has been used as antistatic coating, electrode materials, corrosion inhibitor and sensors.[4, 5] However, PANI is insoluble in most common solvents which renders its processing difficult. One of the objectives is to reduce product cost without losing the desired properties of the components. Moreover, for some applications, like ink-jet printing, stable aqueous dispersions are needed. Armes and collaborators were the first to report the synthesis and characterization of colloidal polyaniline-silica composites by chemical oxidative polymerization of aniline in the presence of colloidal silica $(D \approx 20 \mathrm{~nm})$. The submicronic aggregates formed $(D=250 \pm 50 \mathrm{~nm})$ showed raspberry morphology in which the silica particles were glued together by the PANI.[6-10] At the meantime, it was shown that polymerization of aniline at surfaces (silica gel, polymer particles) occurred before precipitation polymerization in the bulk. Based on the concept of heterogeneous catalysis this has been attributed to higher reactivity of adsorbed molecules compared to that occurring in the bulk. The adsorption of oligomers produces the initiation centers which start the growth of PANI chains.[11-14] Moreover, there have been some evidences that the presence of insulating silica does not affect significantly the electrical properties. Indeed, the incorporation of inorganic materials such as silica into PANI has even been shown to enhance conductivities.[15-17] PANI-silica nanocomposites have also been used as electrorheological fluids showing higher yield stress, higher polarizability and faster response to electric field compared to pure PANI. [18-20]

Core-shell structures based on a silica core and a PANI shell were firstly reported by Armes and collaborators in 1991.[21] In this study, PANI-silica composites were prepared by in-situ polymerization of aniline in the presence of micrometer silica particles using a low oxidant and monomer concentration to slow the reaction down and to promote polymerization on the 
surface rather than in the bulk. In this case, SEM micrographs have shown that the silica particles were not uniformly coated with polyaniline. In 2006, Jang and collaborators described the formation of $\mathrm{SiO}_{2}$-PANI core-shell nanoparticles less than $30 \mathrm{~nm}$ in diameter with a thin PANI layer (2 nm) obtained by in-situ polymerization.[22] Later on, the same authors obtained core-shell structures using self-stabilized dispersion polymerization carried out in an aqueous/organic liquid system at $-30^{\circ} \mathrm{C}$. Particles with diameter ranging from 18 to $130 \mathrm{~nm}$ were obtained depending on the silica NPs used. The polymer chains were grown parallel to the silica resulting in an enhancement of electrical conductivities.[17] Note that other examples of core-shell $\mathrm{SiO}_{2}$-PANI particles can be found in the literature but in these cases, a chemical grafting of the monomer on the silica surface was performed prior to polymerization.[23] Recently, two groups have reported the synthesis of monodisperse mesoporous carbon nanospheres (MCNs) by combining polymerization of aniline with coassembly of colloidal silica nanoparticles. Starting from commercial $\mathrm{SiO}_{2}$ nanoparticles (7-42 $\mathrm{nm}$ ) they performed the polymerization of aniline and obtained polyaniline-silica nanospheres where $\mathrm{SiO}_{2}$ NPs were uniformly embedded in the PANI matrix. After carbonization and removal of the $\mathrm{SiO}_{2}$ template, MCNs with the desired mesopores were obtained.[24, 25]

Taking this literature into account, it seems that polymerization of aniline in the presence of small silica NPs has led to discrepancy results. Armes, Müllen and Asefa's works look much alike.[21, 24, 25] In their work, raspberry like structures were obtained while Jang and collaborator described the formation of core-shell $\mathrm{SiO}_{2}$ - PANI particles.[22] This latter result was rather intriguing to us.[22] Indeed, the formation of the core-shell structure was ascribed to the fact that anilinium monomer adsorbed onto negatively charged silica surface. The synthesis was performed at $\mathrm{pH}=3$ and the authors claimed that the zeta potential of Ludox TM-40 silica at this $\mathrm{pH}$ was $-50.3 \mathrm{mV}$. This value is much higher than those classically observed with this kind of particles $(\xi=-5 \mathrm{mV})$. [24, 26] In the present paper, we performed an in depth study of the chemical polymerization of aniline in the presence of silica particles using a procedure close to the one described by Jang and collaborators.[22] In most studies, commercial silica sols have been used. However, these sols have been stabilized by adding counter-cation like $\mathrm{NH}_{4}{ }^{+}, \mathrm{Na}^{+}, \mathrm{Li}^{+}$at $\mathrm{pH}$ where they are negatively charged. The amount and nature of the stabilizers used are sometimes difficult to determine. Therefore, we decided to prepare our own silica particles of different sizes $\left(D_{\mathrm{h}} \approx 90\right.$ and $\left.300 \mathrm{~nm}\right)$ by Stöber process and to characterize them carefully. Then, we performed the polymerization of aniline in the presence of silica particles under different experimental conditions (temperature, concentration of aniline, concentration of silica, particles size). The resulting PANI-silica 
composites were finally characterized by FT-IR, SEM observations and electrical conductivities measurements.

\section{Experimental section}

\subsection{Chemicals}

The following chemicals were purchased and used as received: tetraethoxysilane $98 \%$ (TEOS) from Acros, ethanol 99.7\% from VWR, ammonia 35\% $\left(\mathrm{NH}_{3}\right)$ and ammonium persulfate (APS) from Acros Organics, Aniline 99.5\% (Ani) from VWR, hydrochloric acid 1.0 M ( $\mathrm{HCl}$ ) from Fisher and Ludox ${ }^{\circledR}$ TM-40 colloidal silica from Aldrich.

\subsection{Characterization}

Scanning Electron Micrographs (SEM) were obtained using a HITACHI S4800 FEG HR Scanning Electron Microscope or a FEI Quanta FEG 200 apparatus without previous metallization of the samples.

The zeta potential and hydrodynamic sizes of particles were measured on a Malvern Zetasizer NanoZS equipped with a $\mathrm{He}-\mathrm{Ne}$ laser $(\lambda=632.8 \mathrm{~nm})$ at $25^{\circ} \mathrm{C}$. For hydrodynamic size measurements, the back-scattered mode was used at an angle of $173^{\circ}$. The particles were diluted to 0.5 g. $\mathrm{L}^{-1}$ in $10^{-2}$ mol. $\mathrm{L}^{-1} \mathrm{NaCl}$. $\mathrm{pH}$ was adjusted with small amount of $\mathrm{HCl}$ or $\mathrm{NaOH}$ and read just before measurement with a Mettler Toledo SevenEasy. Nanoparticle suspensions were sonicated for $2 \mathrm{~min}$ before being injected into the cell and left to equilibrate for 2 min prior to measurement. The correlation function of Dynamic Light Scattering (DLS) was analyzed via the general purpose method (NNLS) to obtain the distribution of diffusion coefficients of the solutes. The apparent equivalent hydrodynamic diameters $\left(D_{\mathrm{H}}\right)$ were determined from the cumulant method using the Stokes-Einstein equation. Mean diameter values were obtained from duplicate runs. The Smoluchowski approximation was used to calculate the $\zeta$-potential from the measured electrophoretic mobility of the particles $\left(U_{\mathrm{E}}\right)$. The Smoluchowski approximation is applicable when the particle size is larger than the Debye length of the electrical double layer in a polar medium. The reported $\zeta$-potential values are an average of two measurements per sample, where each measurement is an average of 20 subruns.

Infrared spectra were recorded with a $2 \mathrm{~cm}^{-1}$ resolution on a Bruker Vertex70 FTIR spectrometer with the use of a Platinum ATR accessory equipped with a diamond crystal.

A Micromeritics Tristar II BET apparatus was used to measure the surface area of the silica particles. Prior to analysis, the powders were degassed under vacuum at $120^{\circ} \mathrm{C}$ for $2 \mathrm{~h} 30$. 
Thermogravimetric analysis (TGA) was carried out on a TA instruments Q600 in an alumina crucible under an air flow with a heating rate of $10{ }^{\circ} \mathrm{C} \cdot \min ^{-1}$ up to $850{ }^{\circ} \mathrm{C}$.

The surface composition was monitored by X-ray photoelectron spectroscopy (XPS) on an Versaprobe 5000 (Physical Electronics). The X-ray excitation was provided by a monochromatic Al $\mathrm{K} \alpha(1486.7 \mathrm{eV})$ source. Analyzed surface has a $200 \mu \mathrm{m}$ diameter. The background signal was removed using the Shirley method.[27] The surface atomic concentrations were determined from photoelectron peak areas using the atomic sensitivity factors reported by Scofield corrected by transfer function of analyser.[28] Binding energies (BE) of all core levels were referred to the $\mathrm{C}-\mathrm{C} / \mathrm{C}-\mathrm{H}$ of $\mathrm{C} 1 \mathrm{~s}$ carbon at $284.8 \mathrm{eV}$

The electrical conductivities were measured by the van der Pauw technique of four points probe measurements on compressed pellets of the dried nanocomposites at room temperature. The four probes are nickel contacts coated by a thin layer of gold.[29, 30]

\subsection{Synthesis}

\subsubsection{Synthesis of silica particles}

$\mathrm{NH}_{3}$ was added to a mixture of EtOH and distilled water and the resulting solution was stirred at room temperature under magnetic stirring $(250 \mathrm{rpm})$ for $20 \mathrm{~min}$. Two ammonia concentrations were used, $1.0 \mathrm{~mol} . \mathrm{L}^{-1}$ and $0.3 \mathrm{~mol} . \mathrm{L}^{-1}$. Then, TEOS was added dropwise and the reaction was kept under magnetic stirring for $24 \mathrm{~h}$ at room temperature resulting in a white suspension of colloidal silica. $\mathrm{The}^{\mathrm{SiO}_{2}}$ particles were then collected by centrifugation during 10 minutes at $16000 \mathrm{rpm}$ and washed three times with ethanol and several times with distilled water until the $\mathrm{pH}$ of the supernatant reached 8.5 - 9. Small addition of $\mathrm{HCl}\left(1 \mathrm{~mol} . \mathrm{L}^{-1}\right)$ could be performed in order to fasten the $\mathrm{pH}$ stabilization. Each washing step involved a sonication step. To finish, the products were dried at $80^{\circ} \mathrm{C}$ for 16 hours. The amounts of reagents used are given in Table 1.

Table 1. Reagents and quantities used in the preparation of silica particles.

\begin{tabular}{cccc}
\hline $\begin{array}{l}\mathrm{V}_{\mathrm{EtOH}} \\
(\mathrm{mL})\end{array}$ & $\begin{array}{c}\mathrm{V}_{\mathrm{H} 2 \mathrm{O}} \\
(\mathrm{mL})\end{array}$ & $\begin{array}{c}\mathrm{V}_{\mathrm{NH}}, 35 \% \\
(\mathrm{~mL})\end{array}$ & $\begin{array}{c}\mathrm{V}_{\mathrm{TEOS}} \\
(\mathrm{mL})\end{array}$ \\
\hline 124.4 & 8.6 & 8.3 & 6.6 \\
132.3 & 5.6 & 2.4 & 6.6 \\
\hline
\end{tabular}




\subsubsection{Polymerization of aniline in the presence of silica particles}

A specific amount of silica nanoparticles $(150 \mathrm{mg}$ or $300 \mathrm{mg}$ ) was dispersed in $50 \mathrm{~mL}$ of distilled water under ultrasound. $172.8 \mu \mathrm{L}$ of aniline were added ([Aniline] $=0.037 \mathrm{~mol} . \mathrm{L}^{-1}$ ) and the $\mathrm{pH}$ was stabilized to 3.5 by addition of $\mathrm{HCl} 1.0 \mathrm{M}$. The initial weight ratios silica to aniline $\mathrm{w}_{\text {silica/aniline }}$ were thus equal to 0.8 or 1.7 . The resulting suspension was stirred for 90 min at $21{ }^{\circ} \mathrm{C}$ or $0.3 \pm 0.2{ }^{\circ} \mathrm{C}$ to allow adsorption of anilinium cations onto silica particles. 2 $\mathrm{mL}$ of an aqueous solution of APS oxidant was then added dropwise to the suspension to obtain ratio [APS]/[Ani] between 1.0 and 1.5. The reaction mixture was stirred until the end of the polymerization process as observed by kinetic measurements or formation of the green color and centrifuged. The resulting precipitate was washed several times with water and ethanol. The final products were dried at $80^{\circ} \mathrm{C}$ for 16 hours.

\section{Results and discussion}

\subsection{Synthesis and characterization of silica particles}

Monodisperse silica particles were synthesized through the sol-gel method proposed by Stöber et al.[31] and Matsoukas and Gulari.[32] Two different concentrations of ammonia were used: 0.3 and 1.0 mol.L $\mathrm{L}^{-1}$. Fig. 1 shows SEM micrographs of the silica particles obtained using these two ammonia concentrations. As expected, the silica nanoparticles were all spherical and uniform in size. By counting 100 spheres through SEM observations mean diameter $D_{\text {SEM }}$ was estimated to be $285 \pm 5 \mathrm{~nm}$ for silica particles obtained using ammonia at a concentration of 1 mol. $\mathrm{L}^{-1}$. Particles size decreased to $80 \pm 3 \mathrm{~nm}$ for an ammonia concentration of $0.3 \mathrm{~mol} . \mathrm{L}^{-1}$. DLS measurements were also performed to determine the hydrodynamic diameters ( $\left.D_{\text {DLS }}\right)$ of the particles in aqueous solutions. The diameters obtained by DLS $\left(D_{\mathrm{h}}=320 \pm 70 \mathrm{~nm}\right.$ and $\left.90 \pm 15 \mathrm{~nm}\right)$ were only slightly larger than those obtained by SEM measurements (Fig. 2).

Figure 3 shows the zeta potential-pH-profile for the different silica particles. Negative zeta potentials were measured at $\mathrm{pH}$ higher than 3 . The zeta potential for silica particles increases with increasing $\mathrm{pH}$, because the surface charge density of silica is strongly dependent on $\mathrm{pH}$. These results are in accordance with those reported earlier.[33] BET measurements revealed a surface area of $18.3 \pm 0.9 \mathrm{~m}^{2} \cdot \mathrm{g}^{-1}$ and $67.4 \pm 3.4 \mathrm{~m}^{2} \cdot \mathrm{g}^{-1}$ for the particles with $D_{\mathrm{h}} \approx 300 \mathrm{~nm}$ and $90 \mathrm{~nm}$, respectively. 

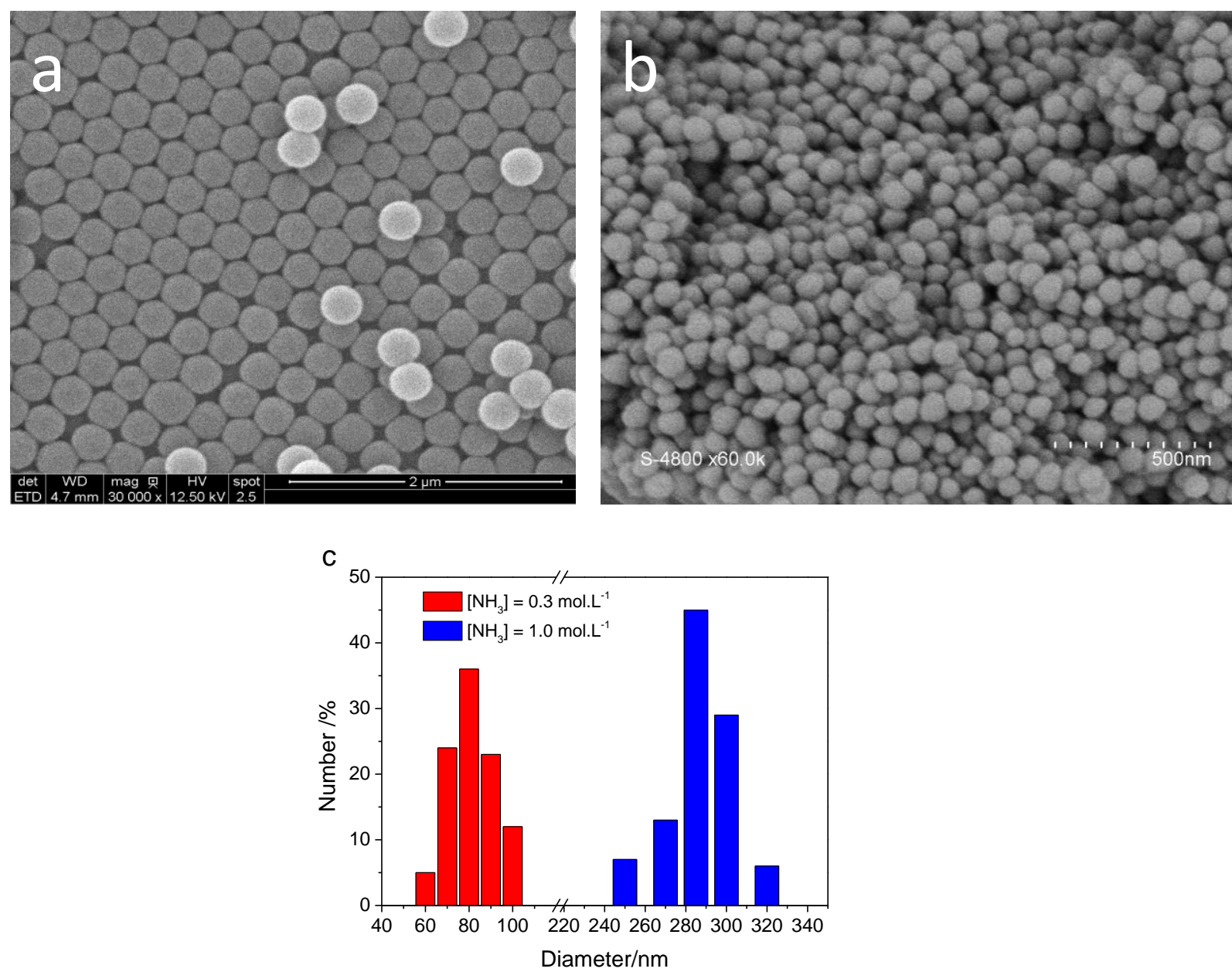

Fig.1 SEM images of silica particles synthesized using ammonia concentrations of (a) 1.0 mol. $\mathrm{L}^{-1}$ and (b) $0.3 \mathrm{~mol} . \mathrm{L}^{-1}$ with their size distribution (c).

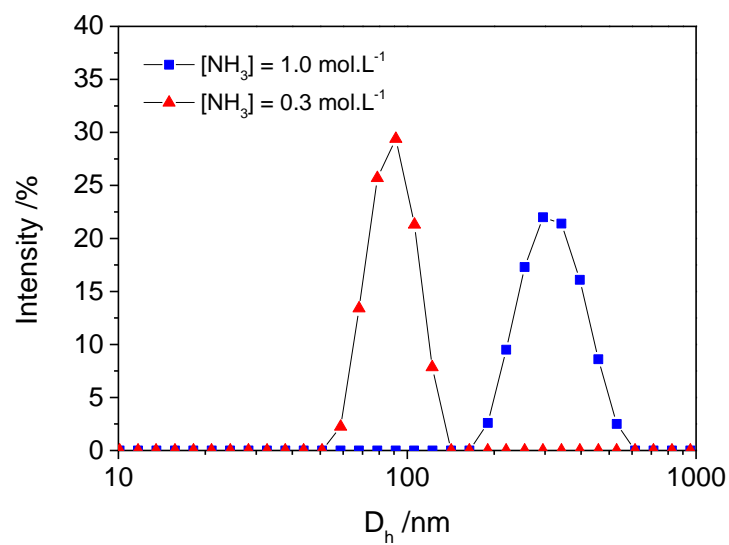

Fig. 2 Particles size distributions measured by DLS.

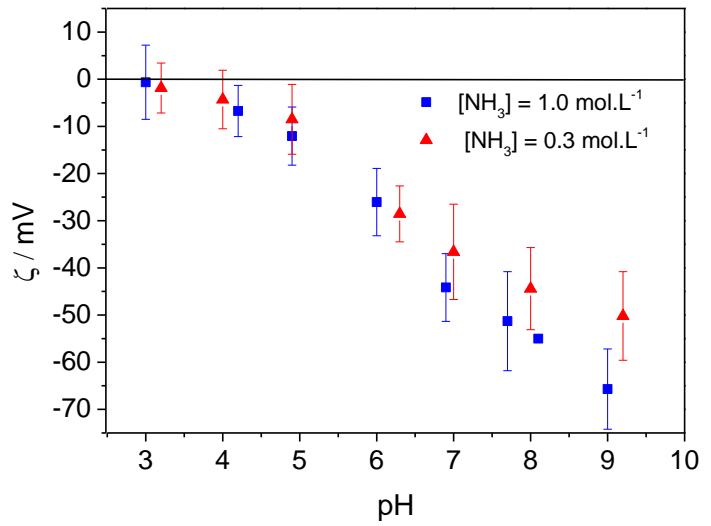

Fig. $3 \xi$ potential $v s \mathrm{pH}$ curves for the silica particles. 


\subsection{Synthesis of polyaniline-silica composites}

Our initial objective was to prepare silica-polyaniline core-shell particles. For this, we followed the protocol described by Jang and collaborators in 2006.[22] Since aniline has a $\mathrm{pKa}$ value of $4.58,[34]$ they performed their experiments at $\mathrm{pH}=3.0$ to favor adsorption of anilinium cations onto negatively charged silica. At this $\mathrm{pH}$, their zeta potential was equal to $50 \mathrm{mV}$ whereas we found a value close to 0 . We thus performed a slight modification to their procedure and used a $\mathrm{pH}=3.5$ instead of $\mathrm{pH}=3.0$ to obtain slightly negatively charged particles. Our syntheses were also performed using ammonium persulfate (APS) as the oxidant.

The kinetics of aniline (Ani) polymerization were followed by temperature and $\mathrm{pH}$ changes for the reactions performed at $21^{\circ} \mathrm{C}$ (Fig. 4). In a first series of experiments, we used silica particles of $D_{\mathrm{h}} \approx 300 \mathrm{~nm}$. Various oxidant to monomer ratios [APS]/[Ani] $=1.0,1.25,1.50$

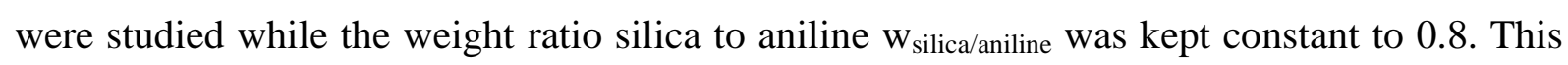
initial weight ratio was chosen as a previous study has demonstrated that when the ratio is below 0.2, the synthesis of PANI-silica composites led to non uniform morphology with a mixture of polyaniline nanotubes and PANI-silica nanogranules.[35] For comparison, PANI was also prepared using the same experimental procedure in the absence of silica. Several papers have already dealt with the effect of the initial acidity of the medium on the aniline oxidation. However, in most cases, highly acidic medium with $\mathrm{pH}$ close to 2 or with medium acidity with $\mathrm{pH}$ superior to the $\mathrm{pKa}$ of aniline have been studied. Here, we started our experiments with a $\mathrm{pH}$ close to $\mathrm{pKa}-1$ where anilinium cations concentration is ten times higher than aniline. However, despite a major contribution of anilinium cations, the scenario is different to that encountered in highly acidic media where an induction period followed by a single exothermic phenomenon was always observed.[14] Our results looked much alike those obtained in medium acidic media ( $\mathrm{pH}>\mathrm{pKa}$ aniline). The oxidation in the presence of silica started immediatly as indicated by the drop of $\mathrm{pH}$ values from 3.5 to 2.5 due to the formation of sulfuric acid concomitantly with an increase of the temperature. The first exothermic phenomenon is immediately followed by a second one when [APS]/[Ani] $=1.25$ and 1.5 while for $[\mathrm{APS}] /[\mathrm{Ani}]=1.0$, the two exothermic phenomena were well separated by an athermal step. As the ratio [APS]/[Ani] increased from 1.0 to 1.5, the total heat given off for polymerization of aniline increased. [36] Comparison of the curves obtained using the same $[$ APS] $/[$ Ani] ratio $=1.25$ in the presence or absence of silica clearly evidenced that the presence of silica increased the amount of heat released during the first polymerization step. 
This observation is in contrast to what was reported by Stejskal and collaborators who observed a decrease of heat released during the first polymerization step in the presence of silica.[35] In their case, the reaction was performed at an initial $\mathrm{pH}$ equal to 7.0 where silica particles were negatively charged. To explain their observations they proposed that homogeneous oxidation of aniline in the aqueous phase governed the first polymerization step. As such, partial adsorption of aniline onto silica surface decreased its concentration into the aqueous phase resulting in a decrease of the total heat released. The reason why we observed an increase of the heat released in the presence of silica cannot be rationalized by their explanation.
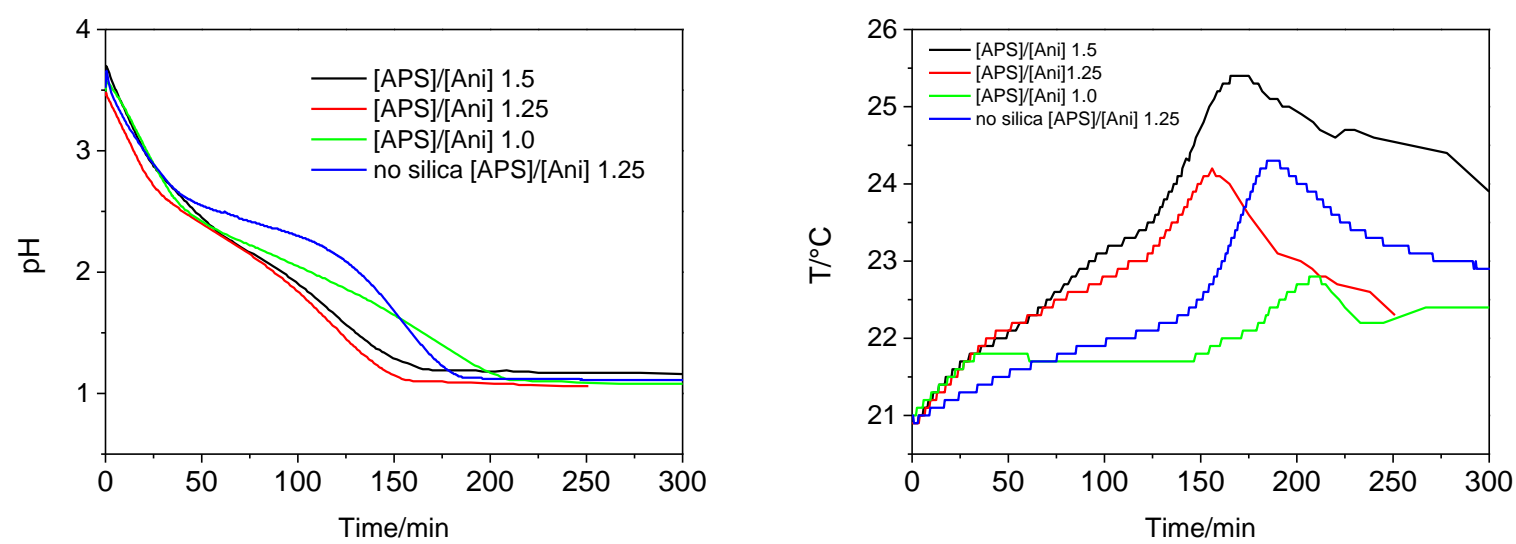

Fig. 4 (left) $\mathrm{pH}$ and (right) temperature changes during polymerization of aniline with different $[$ APS $] /[$ Ani $]$ ratio at $\mathrm{w}_{\text {silica/Aniline }}=0.8$ and $D_{\mathrm{h}} \mathrm{SiO}_{2}=300 \mathrm{~nm}$

In a second set of experiments, we increased the ratio $\mathrm{w}_{\text {silica/Aniline }}$ from 0.8 to 1.7 . By assuming a complete conversion of aniline to polyaniline, these ratios correspond to theoretical weight fractions of polyaniline in the composites equal to $54 \%$ and $37 \%$, respectively. The experimental weight ratios of polyaniline were determined by thermogravimetric analysis under air flow and were found to be very close to theoretical ones (53.7 and $34.8 \mathrm{wt} \%$, respectively) (see Fig. S1 in Supporting Information). We also used two different sizes of particles $\left(D_{\mathrm{h}} \approx 300 \mathrm{~nm}\right.$ and $\left.D_{\mathrm{h}} \approx 90 \mathrm{~nm}\right)$ while keeping the [APS]/[Ani] ratio constant to 1.25 (Fig.5). As expected from their higher surface area, silica particles of $D_{\mathrm{h}} \approx 90 \mathrm{~nm}$ have a strong influence on the kinetics. The variations of temperature obtained using silica particles of $D_{\mathrm{h}} \approx 90 \mathrm{~nm}$ resemble those obtained in solutions of strong acids where an induction period was followed by a single exothermic step.[37] This kinetic profile has been shown to be characteristic to the presence of anilinium cations as dominating species that are difficult to 
oxidize.[37] This observation suggested that strong adsorption on silica surface of the remaining aniline molecules occurred. However, surprisingly, the kinetic profile obtained following the $\mathrm{pH}$ is the same for the two particles size. The influence of adding silica particles onto the rate of aniline polymerization has already been demonstrated. The presence of interfaces like silica is indeed known to accelerate the formation of PANI by heterogeneous catalysis.[12, 14, 38] However, to our knowledge, it is the first time that such effect is shown at this $\mathrm{pH}$ and that it influences so strongly the temperature profile. Finally, kinetics were also slightly fasten when the concentration of silica was increased.
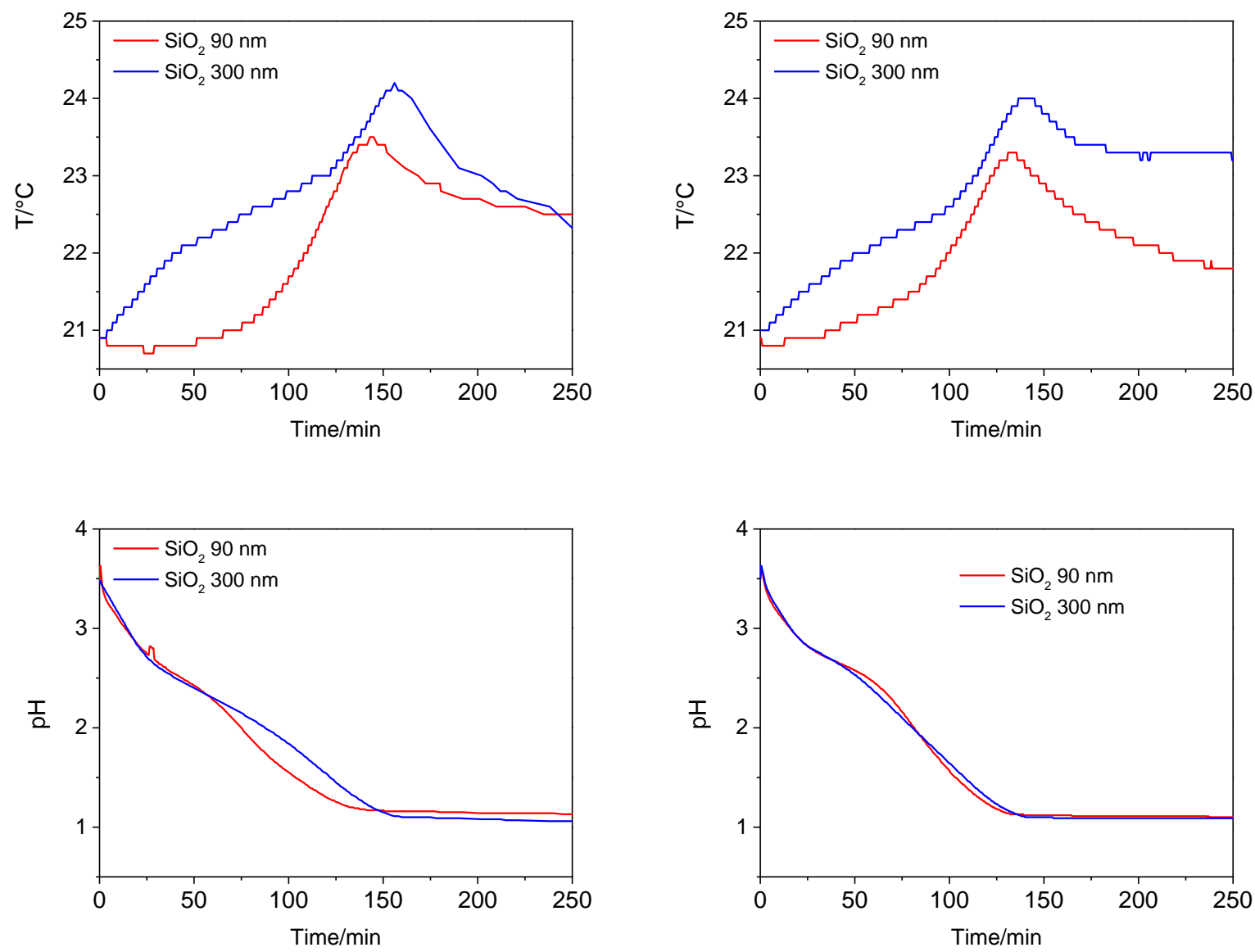

Fig. 5 Temperature and $\mathrm{pH}$ changes during polymerization of aniline with [APS]/[Ani] $=1.25$ at $\mathrm{w}_{\text {silica/Aniline }}=0.8$ (left) and 1.7 (right) with $\mathrm{SiO}_{2}$ particles $\left(D_{\mathrm{h}}=90 \mathrm{~nm}\right.$ and $\left.300 \mathrm{~nm}\right)$.

\subsection{Infrared spectroscopy}

ATR-FTIR spectra of silica, PANI and composite particle powders are shown in Fig. 6. The spectrum of naked colloidal $\mathrm{SiO}_{2}$ particles shows four characteristic absorption bands arising from asymmetric vibration of Si-O-Si siloxane bonds $\left(1065 \mathrm{~cm}^{-1}\right)$, asymmetric vibration of Si$\mathrm{OH}\left(950 \mathrm{~cm}^{-1}\right)$, symmetric vibration of Si-O-Si $\left(795 \mathrm{~cm}^{-1}\right)$ and racking mode of Si-O-Si (450 
$\mathrm{cm}^{-1}$ ).[39] The spectra of the PANI-silica composites contain these vibration bands characteristic of silica but also vibration bands characteristic of the formation of the emeraldine salt form of polyaniline. Indeed, the bands at $1570-1590$ and $1480-1500 \mathrm{~cm}^{-1}$ can be assigned to quinoid (Q) ring and benzenoid (B) ring stretching, respectively. The band at $1300-1310 \mathrm{~cm}^{-1}$ is due to the $\mathrm{C}-\mathrm{N}$ stretching of secondary aromatic amine when the band which appears as a shoulder at $1200-1220 \mathrm{~cm}^{-1}$ can be attributed to the $\mathrm{C}-\mathrm{NH}^{+}$stretching, this latter band being characteristic of polaron form of emeraldine salt.[35, 40] Moreover, in the composite spectra, the broad intense band appearing between 1000 and $1150 \mathrm{~cm}^{-1}$ is mainly due to the siloxane bonds but it also contains a shoulder at $1150 \mathrm{~cm}^{-1}$ that can be attributed to the stretching vibration of $-\mathrm{NH}^{+}=$(in the $\mathrm{B}-\mathrm{NH}^{+}=\mathrm{Q}$ segment) in bipolaron form of emeraldine salt.[35, 40] Other $\mathrm{C}-\mathrm{H}$ bands due to the presence of polyaniline are visible at 860-880, 690700, and 570-580 $\mathrm{cm}^{-1}$.[41, 42] Compared to pure PANI, the PANI-silica composites showed a shift to higher wavenumbers of the bands located at 1290 and $1562 \mathrm{~cm}^{-1}$ characteristic of silica-PANI interactions. These shifts are slightly higher when smaller particles are used $(\Delta v$ $=12 \mathrm{~cm}^{-1}$ for $\mathrm{SiO}_{2} D_{\mathrm{h}}=90 \mathrm{~nm}$ and $\Delta v=10 \mathrm{~cm}^{-1}$ for $\mathrm{SiO}_{2} D_{\mathrm{h}}=300 \mathrm{~nm}$ ).

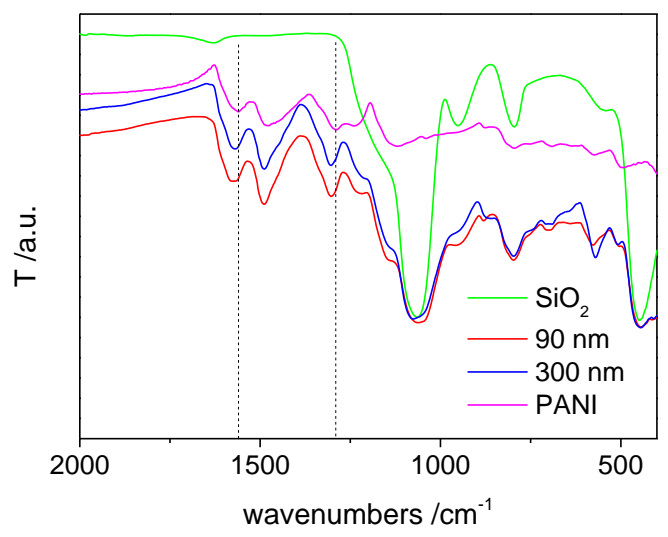

Fig.6 ATR-FTIR spectra of $\mathrm{SiO}_{2}$, PANI and PANI-silica composite powders with particles of $D_{\mathrm{h}}=90 \mathrm{~nm}$ and $300 \mathrm{~nm}$.

\subsection{Morphology}

Fig. 7 shows representative SEM micrographs of the composites obtained under the different conditions described above with those obtained at $0{ }^{\circ} \mathrm{C}$. With a PANI content of $54 \%$ $\left(\mathrm{w}_{\text {silica/aniline }}=0.8\right)$ the SEM images A-B in Fig.7 contain a mixture of PANI granules, PANI@SiO $\mathrm{S}_{2}$ particles and partially or uncovered silica particles. In this case, the PANI content might be too large to accommodate all polyaniline at silica surface leading to the 
formation of polyaniline granule (Fig $7 \mathrm{C}$-E). Indeed, using the equation derived by Lascelles and Armes, [43] the theoretical overlayer thicknesses are estimated around $60 \mathrm{~nm}\left(D_{\mathrm{h}} \mathrm{SiO}_{2}=\right.$ $300 \mathrm{~nm})$ and $20 \mathrm{~nm}\left(D_{\mathrm{h}} \mathrm{SiO}_{2}=90 \mathrm{~nm}\right)$, respectively. However, even when a lower PANI content (37\%) was used, polyaniline granules were still observable with the silica particles of $D_{\mathrm{h}}=300 \mathrm{~nm}$. (Fig. C-D). In this case, the theoretical overlayer thickness was estimated around $35 \mathrm{~nm}$. Surface analysis was performed by XPS on the samples obtained with a PANI content of $37 \%$. The XPS survey spectra in figure 8 shows, besides the presence of nitrogen due to PANI, a non-negligible silicon atom contents confirming the uncomplete coating of the silica particles. For the silica particles with $D_{\mathrm{h}}=300 \mathrm{~nm}$ the $\mathrm{Si} / \mathrm{N}$ atom ratio on the surface is equal to 4.26 a value close to the one reported for PANI/MCM-41[38] while it is equal to 8.07 for silica particles with $D_{\mathrm{h}}=90 \mathrm{~nm}$ (Table S1). Interestingly, in accordance with the differences observed in kinetic profiles, the SEM images of the composites samples obtained using smaller silica particles are rather peculiar. Indeed, they revealed the formation of particles with raspberry-like morphology (Fig. 7 F-H). Our results are thus comparable to those obtained previously in highly acidic media.[6] During the course of aniline polymerization, the $\mathrm{pH}$ rapidly fell and the silica surface became quickly positively charged. Interactions between the positively charged silica and PANI might most probably involved halide counteranion $\left(\mathrm{Cl}^{-}\right)$in $\mathrm{S}^{+} \mathrm{XI}^{-}$pathway as reported for the formation of M41S silicate mesophase.[24, 44]

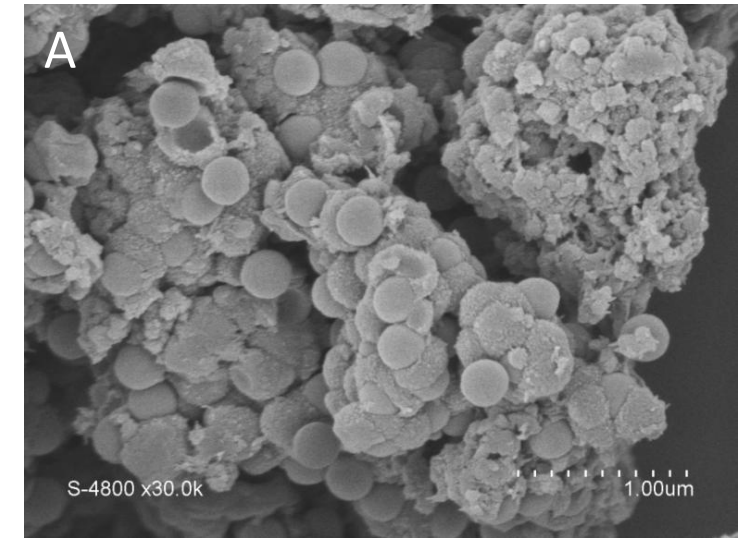

$[$ APS $] /[$ Ani $]=1.25 \mathrm{w}_{\text {Silica } / \text { Aniline }}=0.8, \mathrm{~T}=0^{\circ} \mathrm{C}, D_{\mathrm{h}}=300 \mathrm{~nm}$

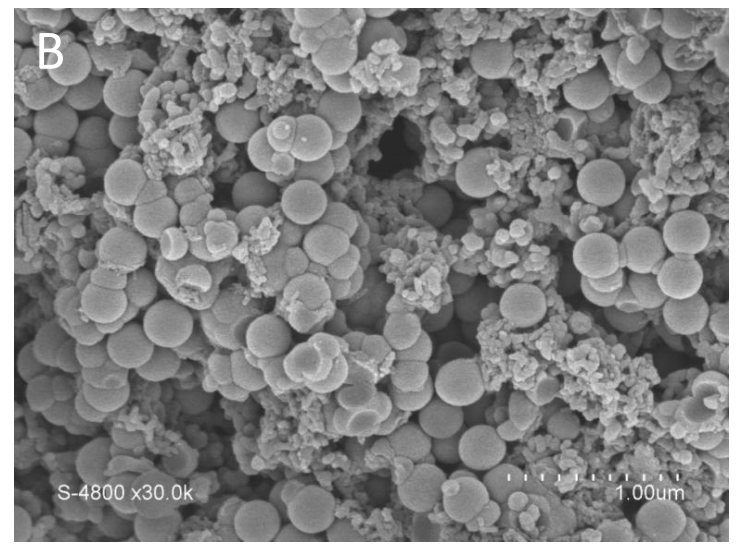

$[$ APS $] /[$ Ani $]=1.25 \mathrm{w}_{\text {Silica/Aniline }}=0.8, \mathrm{~T}=21^{\circ} \mathrm{C}, D_{\mathrm{h}}=300 \mathrm{~nm}$ 


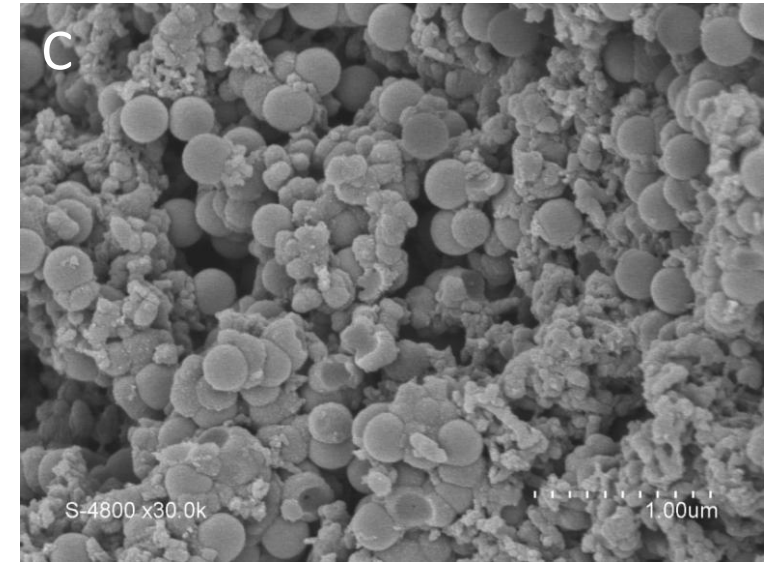

$[$ APS $] /[$ Ani $]=1.25 \mathrm{w}_{\text {Silica } / \text { Aniline }}=1.7, \mathrm{~T}=0^{\circ} \mathrm{C}, D_{\mathrm{h}}=300 \mathrm{~nm}$

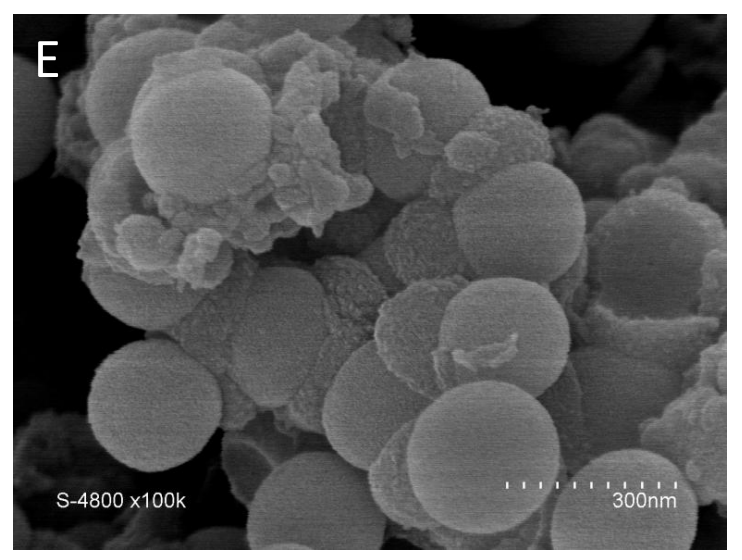

$[$ APS $] /[$ Ani $]=1.25 \mathrm{w}_{\text {Silica/Aniline }}=1.7, \mathrm{~T}=21^{\circ} \mathrm{C}, D_{\mathrm{h}}=300 \mathrm{~nm}$

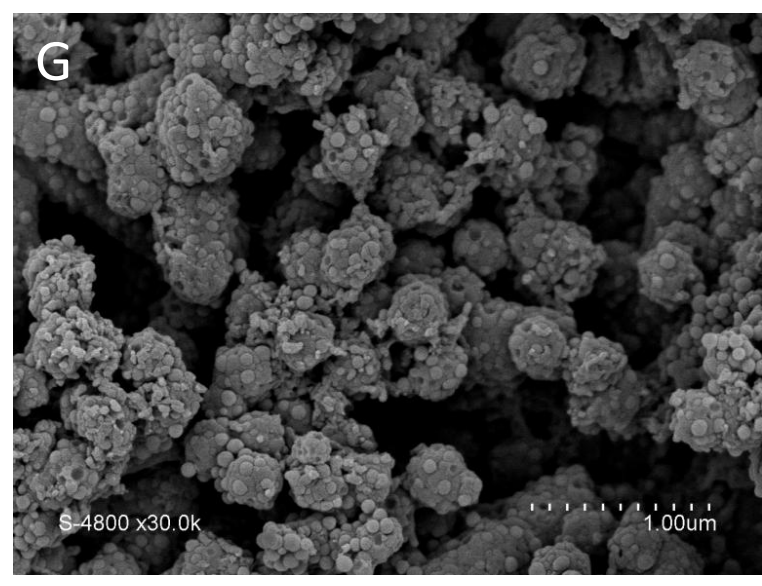

$[$ APS $] /[$ Ani $]=1.25 \mathrm{w}_{\text {Silica } / \text { Aniline }}=1.7, \mathrm{~T}=21^{\circ} \mathrm{C}, D_{\mathrm{h}}=90 \mathrm{~nm}$

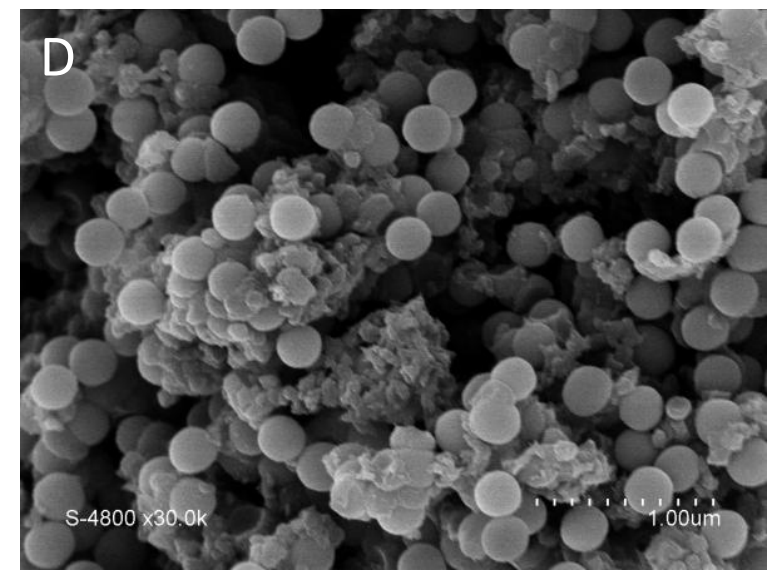

$[$ APS $] /[$ Ani $]=1.25 \mathrm{w}_{\text {Silica/Aniline }}=1.7, \mathrm{~T}=21^{\circ} \mathrm{C}, D_{\mathrm{h}}=300 \mathrm{~nm}$

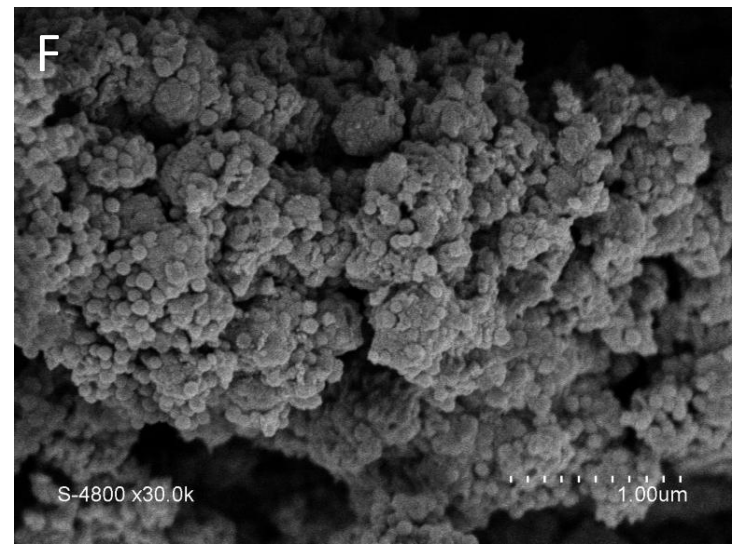

$[$ APS $] /[$ Ani $]=1.25 \mathrm{w}_{\text {Silica/Aniline }}=0.8, \mathrm{~T}=21^{\circ} \mathrm{C}, D_{\mathrm{h}}=90 \mathrm{~nm}$

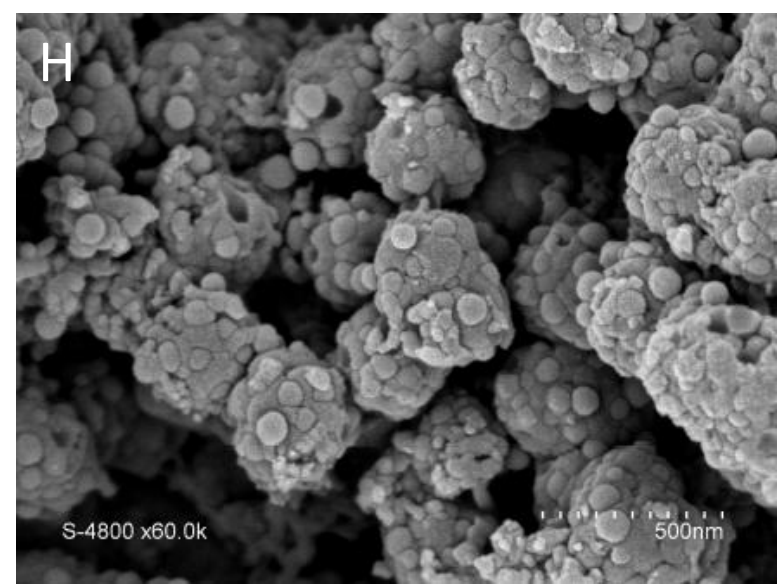

$[$ APS $] /[$ Ani $]=1.25 \mathrm{w}_{\text {Silica/Aniline }}=1.7, \mathrm{~T}=21^{\circ} \mathrm{C}, D_{\mathrm{h}}=90 \mathrm{~nm}$

Fig. 7 SEM images of the PANI-silica composites obtained under various experimental procedures. 


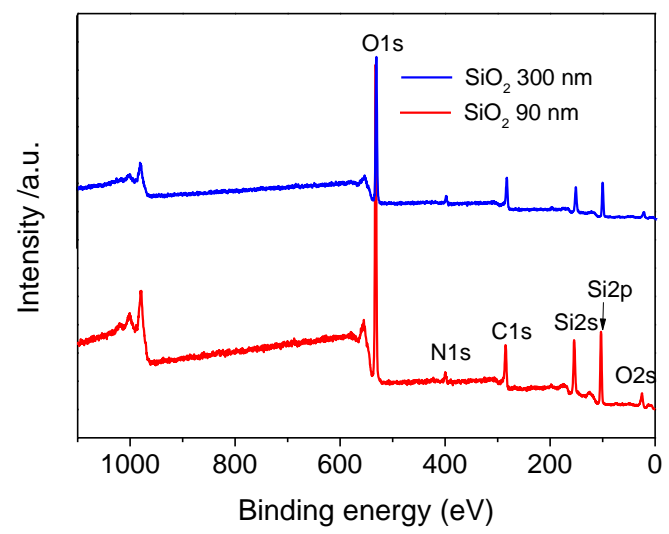

Fig.8 XPS survey spectra of PANI-silica composites with w $_{\text {Silica/Aniline }}=1.7$.

\subsection{Electrical conductivity}

The conductivity values determined on compressed pellets are summarized in Table 2. Moderate conductivities were observed for all samples, even for pure PANI. This is in accordance with other reports and is due to the fact that the polymerization was carried out under relatively mild acidic conditions leading to the formation of PANI oligomers and polymers.[35, 37] The PANI-silica composites exhibited lower conductivities than pure PANI and a decrease of conductivity values was also observed with a decrease of PANI content. Interestingly, for a PANI content of 54\%, the conductivity increased when smaller silica particles were used. This is mainly due to the higher compactness of smaller particles when they are pressed into disks.[17] Surprisingly, this was not the case when the PANI content was equal to $37 \%$ i.e the use of larger silica particles led to the highest conductivity value. One explanation might come from morphology differences. Indeed, we observed a striking difference in morphology for a PANI content of $37 \%$ when silica particles of $D_{\mathrm{h}}=90 \mathrm{~nm}$ were used (vide supra). The raspberry-like morphology observed in this latter case may hinder the conduction path as particles in the size-range $150-500 \mathrm{~nm}$ were formed.

Table 2. Electrical conductivities measured at room temperature of the polyaniline-silica composites and pure polyaniline

\begin{tabular}{cccc}
\hline$D_{\mathrm{h}} \mathrm{SiO}_{2}(\mathrm{~nm})$ & $\mathrm{w}_{\text {Silica/Aniline }}$ & PANI content \% & $\sigma\left(\mathrm{S} . c m^{-1}\right)$ \\
\hline- & - & 100 & $6.1 \times 10^{-2}$ \\
300 & 0.8 & 54 & $1.6 \times 10^{-3}$ \\
90 & 0.8 & 54 & $9.3 \times 10^{-3}$ \\
300 & 1.7 & 37 & $4.8 \times 10^{-4}$
\end{tabular}




\subsection{Synthesis of PANI-silica composites using Ludox TM-40}

Of course one might stipulate that our results were not obtained with the same commercial batch as the one used by Jang and collaborators.[22] To withdraw this doubt, we finally decided to use Ludox TM-40 silica suspension as the silica source following their experimental conditions ( $\mathrm{pH}$, concentration of reactants).[22] For comparison, pure polyaniline was also synthesized under the same conditions. SEM micrographs of the obtained sample are in accordance with those previously reported by Jang and collaborators (Fig. S2). However, the hydrodynamic diameter determined by DLS $\left(D_{\mathrm{h}}=230 \mathrm{~nm}\right)$ was larger than the one reported by Jang (Fig. 9) but is in accordance Armes' work.[6] Figure 10 shows the variation of zeta potential as a function of $\mathrm{pH}$ for pristine Ludox TM-40, pure PANI and PANI-silica composites obtained using the Ludox suspension. As expected, the zeta potential of pristine Ludox suspension is sligthy negative at $\mathrm{pH}=3$ while PANI is positively charged at $\mathrm{pH}$ below 8.0.[45] The $\xi$ potential versus $\mathrm{pH}$ profile of the silica-PANI composite is superimposable with the one obtained with pure silica. This proves the absence of polyaniline onto the surface of Ludox particles and that silica-polyaniline core-shell structures are not obtained under these conditions. This result is in accordance with Armes and collaborators' work and is in favor of the formation of inorganic oxide rich surface of raspberry morphology.[7]

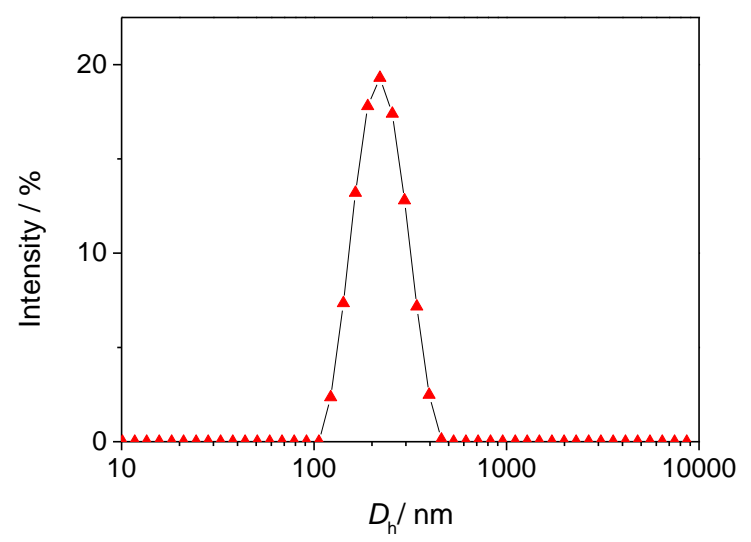

Fig. 9 Particles size distributions measured by DLS

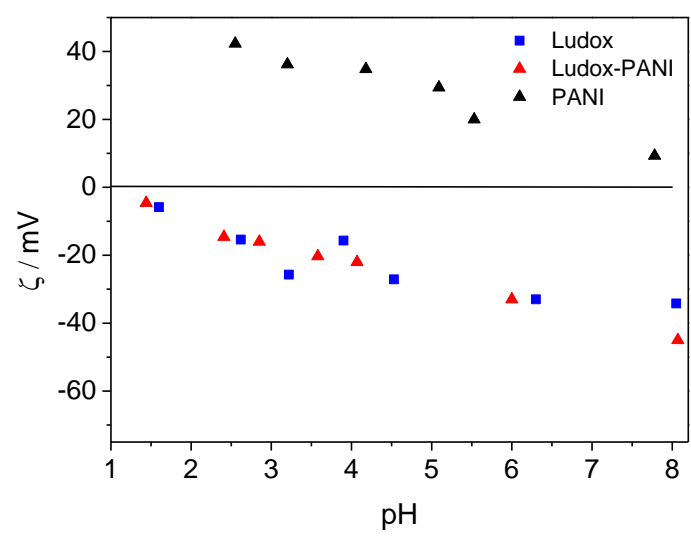

Fig. 10 Comparison of $\xi$ potential $v s \mathrm{pH}$ curves for the Ludox suspension, Ludox-

PANI and PANI 


\section{Conclusions}

The initial objective of this work was to prepare $\mathrm{SiO}_{2}$-PANI core-shell particles. For this, we followed a reported procedure which used medium acidic $\mathrm{pH}$ below the $\mathrm{pKa}$ of aniline molecules and in a region where silica nanoparticles were slightly negatively charged to favor electrostatic interactions between anilinium cations and the silica surface.[22] The course of the polymerization was followed by $\mathrm{pH}$ and temperature changes. Using large particles, the temperature profiles resembled those obtained without silica at medium $\mathrm{pH}$ while in the presence of small silica particles, they were comparable to those obtained using highly acidic medium. Surprisingly, these changes had no influence on $\mathrm{pH}$ profiles. The observation of a single exothermic phenomenon with small silica particles suggested strong adsorption of aniline molecules onto the silica surface. This is in contrast to the expected electrostatic interactions between anilinium cations and silica surface. As the $\mathrm{pH}$ rapidly fell, the silica surface became rapidly negatively charged further preventing any electrostatic interactions.

As such, this study shed light on the fact that core-shell silica-polyaniline particles cannot be obtained under previously reported procedure and this is independent to the size or the source of the particles used. Instead, we have confirmed that larger silica particles became coated with polyaniline (at least in part), while small particles tend to coat polyaniline granules (leading to raspberry-like morphology) as reported before using strong acidic conditions. [6, 21] The formation of raspberry-like morphology led to stronger interactions between silica particles and polyaniline as demonstrated by FT-IR spectroscopy.

\section{Acknowledgements}

N.R. thanks the Ministère de l'Enseignement Supérieur et de la Recherche for a PhD scholarship. Mr Didier Cot from the Institut Européen des Membranes of the University of Montpellier is gratefully acknowledged for the SEM images reported here. The authors also thank Mr Maxime Guerineau from the laboratoire Interdisciplinaire Carnot de Bourgogne Dijon for his help with BET measurements. We are also thankful to Marie-Laure Léonard from ESIREM Dijon, France for obtaining the TGA results reported herein. We wish to thank Dr. Olivier Heintz from the Laboratoire interdisciplinaire Carnot de Bourgogne (UMR-CNRS 6303, France) for carrying out the XPS measurements described in this study. 


\section{References}

[1] C. Sanchez, P. Belleville, M. Popall, L. Nicole, Applications of advanced hybrid organicinorganic nanomaterials: from laboratory to market, Chemical Society Reviews 40 (2) (2011) 696-753.

[2] H. Zou, S.S. Wu, J. Shen, Polymer/silica nanocomposites: Preparation, characterization, properties, and applications, Chemical Reviews 108 (9) (2008) 3893-3957.

[3] A.G. MacDiarmid, "Synthetic metals": A novel role for organic polymers (Nobel lecture), Angewandte Chemie-International Edition 40 (14) (2001) 2581-2590.

[4] J. Anand, S. Palaniappan, D.N. Sathyanarayana, Conducting polyaniline blends and composites, Progress in Polymer Science 23 (6) (1998) 993-1018.

[5] N. Gospodinova, L. Terlemezyan, Conducting polymers prepared by oxidative polymerization: Polyaniline, Progress in Polymer Science 23 (8) (1998) 1443-1484.

[6] M. Gill, S.P. Armes, D. Fairhurst, S.N. Emmett, G. Idzorek, T. Pigott, Particle-size distributions of polyaniline silica colloidal composites, Langmuir 8 (9) (1992) 2178-2182.

[7] M.D. Butterworth, R. Corradi, J. Johal, S.F. Lascelles, S. Maeda, S.P. Armes, Zetapotential measurements on conducting polymer-inorganic oxide nanocomposites particles, Journal of Colloid and Interface Science 174 (2) (1995) 510-517.

[8] S. Maeda, M. Gill, S.P. Armes, Surface characterization of conducting polymer-silica nanocomposites by X-Ray photoelectron spectroscopy, Langmuir 11 (6) (1995) 1899-1904.

[9] J. Stejskal, P. Kratochvil, S.P. Armes, S.F. Lascelles, A. Riede, M. Helmstedt, J. Prokes, I. Krivka, Polyaniline dispersions .6. Stabilization by colloidal silica particles, Macromolecules 29 (21) (1996) 6814-6819.

[10] J. Stejskal, M. Trchova, J. Hromadkova, J. Kovarova, A. Kalendova, The carbonization of colloidal polyaniline nanoparticles to nitrogen-containing carbon analogues, Polymer International 59 (7) (2010) 875-878.

[11] A. Riede, M. Helmstedt, V. Riede, J. Zemek, J. Stejskal, In situ polymerized polyaniline films. 2. Dispersion polymerization of aniline in the presence of colloidal silica, Langmuir 16 (15) (2000) 6240-6244.

[12] S. Fedorova, J. Stejskal, Surface and precipitation polymerization of aniline, Langmuir 18 (14) (2002) 5630-5632.

[13] A. Riede, M. Helmstedt, I. Sapurina, J. Stejskal, In situ polymerized polyaniline films 4. Film formation in dispersion polymerization of aniline, Journal of Colloid and Interface Science 248 (2) (2002) 413-418.

[14] J. Stejskal, M. Trchova, S. Fedorova, I. Sapurina, J. Zemek, Surface polymerization of aniline on silica gel, Langmuir 19 (7) (2003) 3013-3018.

[15] Y.J. Wang, X.H. Wang, J. Li, Z.S. Mo, X.J. Zhao, X.B. Jing, F.S. Wang, Conductive polyaniline/silica hybrids from sol-gel process, Advanced Materials 13 (20) (2001) 15821585 .

[16] Z.W. Niu, Z.H. Yang, Z.B. Hu, Y.F. Lu, C.C. Han, Polyaniline-silica composite conductive capsules and hollow spheres, Advanced Functional Materials 13 (12) (2003) 949954.

[17] M. Kim, S. Cho, J. Song, S. Son, J. Jang, Controllable Synthesis of Highly Conductive Polyaniline Coated Silica Nanoparticles Using Self-Stabilized Dispersion Polymerization, ACS Applied Materials \& Interfaces 4 (9) (2012) 4603-4609.

[18] J.Y. Hong, J. Jang, A comparative study on electrorheological properties of various silica-conducting polymer core-shell nanospheres, Soft Matter 6 (19) (2010) 4669-4671.

[19] Y.D. Liu, F.F. Fang, H.J. Choi, Y. Seo, Fabrication of semiconducting polyaniline/nanosilica nanocomposite particles and their enhanced electrorheological and dielectric 
characteristics, Colloids and Surfaces a-Physicochemical and Engineering Aspects 381 (1-3) (2011) 17-22.

[20] J. Noh, C.M. Yoon, J. Jang, Enhanced electrorheological activity of polyaniline coated mesoporous silica with high aspect ratio, Journal of Colloid and Interface Science 470 (2016) 237-244.

[21] S.P. Armes, S. Gottesfeld, J.G. Beery, F. Garzon, S.F. Agnew, Conducting polymer colloïdal silica composites, Polymer 32 (13) (1991) 2325-2330.

[22] J.S. Jang, J. Ja, B. Lim, Synthesis and characterization of monodisperse silica-polyaniline core-shell nanoparticles, Chemical Communications (15) (2006) 1622-1624.

[23] C.J. Weng, Y.L. Chen, Y.S. Jhuo, Y.L. Lin, J.M. Yeh, Advanced antistatic/anticorrosion coatings prepared from polystyrene composites incorporating dodecylbenzenesulfonic aciddoped SiO2@polyaniline coreshell microspheres, Polymer International 62 (5) (2013) 774782.

[24] G. Wang, Y.H. Sun, D.B. Li, H.W. Liang, R.H. Dong, X.L. Feng, K. Mullen, Controlled Synthesis of N-Doped Carbon Nanospheres with Tailored Mesopores through Self-Assembly of Colloidal Silica, Angewandte Chemie-International Edition 54 (50) (2015) 15191-15196.

[25] X.X. Huang, L.J. Zhou, D. Voiry, M. Chhowalla, X.X. Zou, T. Asefa, Monodisperse Mesoporous Carbon Nanoparticles from Polymer/Silica Self-Aggregates and Their Electrocatalytic Activities, ACS Applied Materials \& Interfaces 8 (29) (2016) 18891-18903.

[26] X.Y. Chen, S.P. Armes, S.J. Greaves, J.F. Watts, Synthesis of hydrophilic polymergrafted ultrafine inorganic oxide particles in protic media at ambient temperature via atom transfer radical polymerization: use of an electrostatically adsorbed polyelectrolytic macroinitiator, Langmuir 20 (3) (2004) 587-595.

[27] D.A. Shirley, High-Resolution X-RAY Photoemission spectrum of valence bands of gold, Physical Review B 5 (12) (1972) 4709-\&.

[28] J.H. Scofield, Hartree--Slater subshell photoionization cross-sections at 1254 and 1487 eV, Journal of Electron Spectroscopy and Related Phenomena 8 (2) (1976) 129-137.

[29] L.J. van der Pauw, A method of measuring specific resistivity and hall effect of disks of arbitrary shape, Philips Res. Rep 13 (1958) 1.

[30] F.E. Jurin, C.C. Buron, N. Martin, C. Filiatre, Preparation of conductive PDDA/(PEDOT:PSS) multilayer thin film: Influence of polyelectrolyte solution composition, Journal of Colloid and Interface Science 431 (2014) 64-70.

[31] W. Stober, A. Fink, E. Bohn, Contolled growth of monodisperse silica spheres in micron size range, Journal of Colloid and Interface Science 26 (1) (1968) 62-69.

[32] T. Matsoukas, E. Gulari, Dynamics pf growth of silica particles from ammonia-catalyzed hydrolysis of tetra-ethyl-orthosilicate, Journal of Colloid and Interface Science 124 (1) (1988) 252-261.

[33] S. Schwarz, K. Lunkwitz, B. Kessler, U. Spiegler, E. Killmann, W. Jaeger, Adsorption and stability of colloidal silica, Colloids and Surfaces a-Physicochemical and Engineering Aspects 163 (1) (2000) 17-27.

[34] D.D. Perrin, Prediction of strengths of some organic bases, Journal of the Chemical Society (OCT) (1965) 5590-5596.

[35] G. Ciric-Marjanovic, L. Dragicevic, M. Milojevic, M. Mojovic, S. Mentus, B. Dojcinovic, B. Marjanovic, J. Stejskal, Synthesis and Characterization of Self-Assembled Polyaniline Nanotubes/Silica Nanocomposites, Journal of Physical Chemistry B 113 (20) (2009) 7116-7127.

[36] Y.P. Fu, R.L. Elsenbaumer, Thermochemistry and kinetics of chemical polymerization of aniline determined by solution calorimetry, Chemistry of Materials 6 (5) (1994) 671-677. 
[37] J. Stejskal, I. Sapurina, M. Trchova, E.N. Konyushenko, Oxidation of aniline: Polyaniline granules, nanotubes, and oligoaniline microspheres, Macromolecules 41 (10) (2008) 3530-3536.

[38] X.M. Feng, G. Yang, Y.G. Liu, W.H. Hou, J.J. Zhu, Synthesis of polyaniline/MCM-41 composite through surface polymerization of aniline, Journal of Applied Polymer Science 101 (3) (2006) 2088-2094.

[39] F.Y. Yang, Y. Chu, S.Y. Ma, Y.P. Zhang, J.L. Liu, Preparation of uniform silica/polypyrrole core/shell microspheres and polypyrrole hollow microspheres by the template of modified silica particles using different modified agents, Journal of Colloid and Interface Science 301 (2) (2006) 470-478.

[40] G. Ciric-Marjanovic, V. Dondur, M. Milojevic, M. Mojovic, S. Mentus, A. Radulovic, Z. Vukovic, J. Stejskal, Synthesis and Characterization of Conducting Self-Assembled Polyaniline Nanotubes/Zeolite Nanocomposite, Langmuir 25 (5) (2009) 3122-3131.

[41] M. Trchova, J. Stejskal, Polyaniline: The infrared spectroscopy of conducting polymer nanotubes (IUPAC Technical Report), Pure and Applied Chemistry 83 (10) (2011) 18031817.

[42] H. Guleryuz, C. Filiatre, M. Euvrard, C. Buron, B. Lakard, Novel strategy to prepare polyaniline-Modified SiO2/TiO2 composite particles, Synthetic Metals 181 (2013) 104-109.

[43] S.F. Lascelles, S.P. Armes, Synthesis and characterization of micrometre-sized, polypyrrole-coated polystyrene latexes, Journal of Materials Chemistry 7 (8) (1997) 13391347.

[44] Q.S. Huo, D.I. Margolese, U. Ciesla, P.Y. Feng, T.E. Gier, P. Sieger, R. Leon, P.M. Petroff, F. Schuth, G.D. Stucky, Generalized synthesis of periodic surfactant inorganic composite-materials, Nature 368 (6469) (1994) 317-321.

[45] Y. Liu, Y. Yang, L. Chen, H. Zhu, Y. Dong, N.S. Alharbi, A. Alsaedi, J. Hu, Efficient removal of $\mathrm{U}(\mathrm{vi})$ from aqueous solutions by polyaniline/hydrogen-titanate nanobelt composites, RSC Advances 6 (61) (2016) 56139-56148. 